Article

\title{
Digital Learning Environment Values of Pre-Service Teachers as a Basis for Successful Professional Self-Realisation: A Case Study
}

Olga Yakovleva

check for updates

Citation: Yakovleva, O. Digital Learning Environment Values of Pre-Service Teachers as a Basis for Successful Professional Self-Realisation: A Case Study. Educ. Sci. 2022, 12, 120. https://doi.org/ 10.3390/educsci12020120

Academic Editor: Ching Sing Chai

Received: 28 December 2021

Accepted: 8 February 2022

Published: 10 February 2022

Publisher's Note: MDPI stays neutral with regard to jurisdictional claims in published maps and institutional affiliations.

Copyright: (C) 2022 by the author. Licensee MDPI, Basel, Switzerland. This article is an open access article distributed under the terms and conditions of the Creative Commons Attribution (CC BY) license (https:// creativecommons.org/licenses/by/ $4.0 /)$.
Institute of Information Technology and Technology Education, Herzen State Pedagogical University of Russia, 48 Moika Emb., 191186 Saint-Petersburg, Russia; oyakovleva@herzen.spb.ru

\begin{abstract}
The paper analyses the value mindsets of pre-service teachers in terms of the digital learning environment (DLE). DLE is considered to be both a system of new tools and methods for teaching activity and a prospective educational eco-system for learning. The DLE value model is based on a psychodidactic approach, which concerns three main constructs-digital content values, communication values, and management values. The research involved 200 pre-service teachers who were asked to complete a questionnaire, evaluating 27 DLE values and opportunities. The results show that pre-service teachers value digital learning content but are not sufficiently ready for its creation; they develop tolerance in communication yet do not have enough skills to show empathy; they appreciate independence in learning management and still need training in professional digital self-presentation. Consequently, professional training and especially internships for pre-service teachers should include a synthesis of traditional (face-to-face) and virtual communication and interaction with children to facilitate mastering an expanded set of competencies for successful professional self-realisation. The findings can be beneficial in terms of e-learning practices, DLE design, and the organisation of internships.
\end{abstract}

Keywords: digital learning environment; pre-service teacher; value; higher education; mindset; digital content; communication; management; self-realisation

\section{Introduction}

The category of the VUCA-world (volatility, uncertainty, complexity, and ambiguity) that first appeared at the end of the 20th century [1] fully manifested itself in the COVID-19 pandemic. Particularly, education faced some new challenges such as the switch to a hybrid educational model [2], new forms of content delivery [3], new formats of communication and interaction [4], instructional resilience [5], and others.

One of the challenges is the new formats of future teachers' internships in the digital learning environment (DLE) [6]. In terms of internship, DLE can serve as a means for modeling professional activities [7], as a platform for peer support [8], and as a facility for expanding experience through observation [9].

Generally, according to the higher educational standards for teacher education in Russia, practical experience in schools and internships take up a significant part of the academic load from the first year of the bachelor's degree study. During the lockdown and distance learning period of 2020-2021, students of Herzen University had a pedagogical internship in blended formats, including new online practices such as online center "MegaHerz", organizing a youth camp during school vacations; thematic webinars for children and parents, online consultations, etc.

A teacher can successfully solve professional problems in any educational environment if he/she is aware of the possibilities, values, limitations, and risks of such an environment. Thus, Akimova et al. [10] studied elements of students' readiness for professional activities and proved that the motivational-axiological component ranks first. Samoderzhenkov et al. [11] associate the psychological readiness of pre-service teachers for professional 
activity with a set of personal characteristics - personality traits, motivation, attitudes, and values. Chao et al. [12] developed a work-values scale for teachers, which included the following dimensions: professional self-realisation, professional self-growth, reflection and challenges, guiding students, social contribution, equality and justice, interpersonal interaction and management, artistic and physical activities, working conditions and benefits, and social status. However, to solve professional problems in DLE, a teacher needs some additional digital, communication, and organisational values and skills.

The purpose of the paper is to analyse pre-service teachers' value mindsets in terms of DLE as both a system of new tools and methods for their future professional activity and as a prospective educational ecosystem for their future students. These issues are important since values are the regulator of any activity.

Consequently, the following research questions arise: What is the value structure of DLE, and how it can be modeled? How do students perceive the DLE values from a professional standpoint? What aspects and opportunities of the environment are students aware of in a sufficient and insufficient measure? Which areas of professional training should be strengthened and adjusted? Additionally, how to create conditions for the effective development of pre-service teachers' professional competencies that will provide successful professional self-realisation is an important question.

\section{Materials and Methods}

\subsection{Literature Review}

The analysis of pre-service teachers' value mindsets in terms of DLE can include ideas of psychological, sociological, and philosophical theories of values. Value is an interdisciplinary characteristic of an object or phenomenon that describes its socio-cultural significance and usefulness. At the same time, value is a foundation of the first step of action (value-purpose-action) [13]. Thus, from a psychological perspective, M. Rokeach suggested terminal values (values-goals) and instrumental values (values-tools) [14]. Shalom H. Schwartz turned to cross-cultural psychology ideas and identified ten universal values organised in four groups [15] followed by numerous clarifications and interpretations. Therefore, a significant amount of research is based on Rokeach's terminal and instrumental values [16,17] and Schwartz's theory of basic human values [18-21]. However, Tuulik et al. [22] claim that Rokeach's value model is not sufficient to describe a current flexible value paradigm as it does not consider enough socio-cultural differences. Concerning the study of educational values, Lubsky and Zaytseva [23] suggested that among current students' values are personalisation of learning, interdisciplinary, interculturality, and new educational practices. Litvinova et al. [24] added energy and optimism to the value picture. Ledovskaya et al. [25] proved that pre-service teachers' values develop during their study period, from a predominantly undivided set of values to self-centered and socially oriented values. McGill et al. [26] outlined teacher-related factors affecting student learning and teacher factors influencing student growth. Both groups of factors include axiological issues, such as trust, collegiality, and closeness among teachers; positive relationships with students; pedagogical content knowledge, etc. Shevtsiv et al. [27] found connections between teachers' professional values and self-realisation. Value-based orientations together with qualities such as achievement motivation, empathy, good nature, and benevolence contribute to professional self-realisation.

From sociological positions, considering teachers as a social community, including subgroups in terms of the level of education or subject area, $\mathrm{Wu}$ [28] studied perceived school values, teacher autonomy, and teacher motivation. The findings showed that elementary school teachers rate these aspects higher and teacher motivation is largely predicted by school values and teacher autonomy.

In philosophy, values are related to morality and ethics. The modern interdisciplinary context that brings together philosophy and informatics is associated with such new areas as the ethics of artificial intelligence and neural networks [29]. Therefore, in teacher education, new objectives of digital-values humanisation arise because in e-courses and 
digital learning platforms teachers and learners interact not only in "person-to-person" but also in "person-intellectual system" paradigms.

Values are associated with self-realisation because they are the basis of action. Odinokaya et al. describe self-realisation as "a free activity, determined by the nature of the goal and the measure of its personal understanding and acceptance. The need for self-realisation is a leading need, the source of personal and semantic activity aimed at continuous self-improvement" [30] p. 2.

What are the requirements of contemporary society in developing a digital economy for the professional values of a teacher? The European Digital Competence Framework for Educators (DigCompEdu) [31] provides a diagnostic toolkit aimed at identifying, among other things, the ethical aspects of teacher activities (netiquette, ethics of interaction, critical perception of information, etc.). The framework also outlines a vector of an active professional position, which is an important aspect of the value-oriented component of teaching activity (values of peer-to-peer learning, networking culture, mutual assistance, cooperation, and collaboration in the DLE). The Digital Competence Framework 2.0 [32], which applies to any citizen, not just a teacher, also makes it possible to highlight several values of the digital environment-knowledge, information and digital content, innovative thinking, collaboration, information safety, and sustainability.

The Russian educational standard for higher education (particularly, pedagogical education) comprises universal competencies and their categories in the context of future professional activities in the digital economy society, including systemic and critical thinking; intercultural interaction and communication; teamwork and leadership; self-organisation and self-development; and life safety [33]. In terms of DLE, ethical and responsible behavior in the digital environment is especially important. Thus, the list of important professional values of a teacher in the context of digitalisation includes teamwork (cooperation), leadership, self-development, openness to novelty, social activity (caring for others), systemic and critical thinking (competent implementation of information processes), and tolerance (intercultural and social).

What is specific for DLE values? A variety of customisable and interactive digital learning content determined the evolution of educational practices-flipped learning, project-based learning, big data learning, immersive learning, precise learning, etc. Networking which is the nature of DLE provides opportunities for transmedia educational products, content sharing, and exchange [34]. Experience in virtual communication and moderation facilitates for the development of social skills, sharing information, egocentric and allocentric elaboration, application and transfer, coordination, and reflection [35]. However, we still witness a second digital divide, in which teacher training does not entirely prepare pre-service teachers to implement the mainstream educational practices. Thus, Martin proved that teachers are not ready to use the opportunities of Google Classroom to develop "21st-century learning skills such as effective communication, critical thinking, collaboration, problem-solving, creativity, and technology use" [36].

One more direction of research is connected with the study of personalisation as one of the key DLE values. Jitpaisarnwattana et al. [37] and Yates et al. underline that personalisation is associated with choices in learning approaches, content, and pace; learners can customise their activities which affects a sense of "ownership and control over the time, place and pace at which they learn" [38] (p. 59).

The gradual mastering and perception of the DLE create the basis for successful professional self-realisation since this environment is a new means and object of teachers' professional activity.

\subsection{Methodology}

In this study, the basis for DLE values systematisation was a psychodidactic approach to DLE design [39], which makes it possible to single out three main constructs—educational resources (digital content), educational interactions, and management. DLE with regard to values should be considered in the context of the principle of complementarity with 
the environment of interpersonal interactions. This is because the modern paradigm of education is based on interpersonal interaction. E-learning and blended learning are optional for school education. Even in the pandemic situation, at the first opportunity, schools switched to face-to-face education, so as not to deprive children of the opportunity to full-fledged socialisation. At the same time, it only is possible to master digital tools, new ways of doing things, and realise the specific capabilities and values of such a learning environment in the digital environment. Therefore, teachers need to be aware of the values and risks of DLE to adequately solve their professional tasks.

Table 1 integrates DLE opportunities ( 27 variables) and values in the context of the psychodidactic approach.

Table 1. DLE opportunities and values.

\section{DLE Opportunities}

\section{DLE Values}

1. Content creation (the opportunity to create educational materials and post them in the environment)

2. Content curation (the opportunity to collect and select relevant content, describe and organise it)

3. Content openness (the ability to go beyond the content of the environment, work with open Internet resources)

Content 4. Interactivity

5. Gamification (the ability to participate in game situations, use game elements)

6. Content multimodality (the ability to choose the form of receiving and presenting information-audio, video, text)
Creativity, lateral thinking, information responsibility, digital ethics, freedom of action, relevance, and novelty of information, educational activity, personalisation

7. Content variability (the ability to choose different sources of information-text documents, electronic textbook, reference, and methodological literature)

\begin{tabular}{|c|c|c|}
\hline $\begin{array}{l}\text { Communication } \\
\text { (interaction) }\end{array}$ & $\begin{array}{l}8 . \\
9 . \\
10 . \\
11 . \\
12 . \\
13 . \\
14 . \\
15 . \\
16 . \\
17 . \\
18 .\end{array}$ & $\begin{array}{l}\text { Customisation } \\
\text { Information responsibility } \\
\text { Perceptions of DLE stakeholder } \\
\text { Teamwork, mutual assistance } \\
\text { Rules of networking } \\
\text { Interaction with stakeholders from other areas of study or profession } \\
\text { Interaction with other peoples, cultures } \\
\text { Tolerance to the opinion, lifestyle } \\
\text { Collective intelligence of a network community } \\
\text { Interaction with emoticons, signs, symbols, memes } \\
\text { Interaction } 24 / 7 \text {, synchronous and asynchronous }\end{array}$ \\
\hline Management & $\begin{array}{l}20 . \\
21 . \\
22 . \\
23 . \\
24 . \\
25 . \\
26 . \\
27 .\end{array}$ & $\begin{array}{l}\text { Management of educational activities-organisation, planning, } \\
\text { control } \\
\text { Self-image creation } \\
\text { Self-knowledge } \\
\text { Choice of management strategies-external, peer, self-management } \\
\text { Teamwork, peer learning, peer assessment } \\
\text { Intelligent technologies—-search engines, intelligent translators, } \\
\text { machine learning } \\
\text { Personal educational path } \\
\text { Digital tools } \\
\text { Feedback from various stakeholders and objects-colleagues, } \\
\text { teachers, social partners, learning analytics }\end{array}$ \\
\hline
\end{tabular}

Digital self-management, digital self-presentation, digital self-identification, range of feedback strategies, peer learning, intellectualisation, time-saving, personalisation, instrumentalisation
Digital empathy, network collaboration, netiquette, interdisciplinary and interdisciplinary communication, intercultural communication, digital tolerance, intellectualisation of communication, visualisation of communication, expansion of communication 
Based on the listed in Table 1 DLE opportunities and values, it is possible to build a visualised model of DLE values as an extension and enrichment of the traditional educational environment values that evolve from mainly interpersonal interactions (Figure 1).

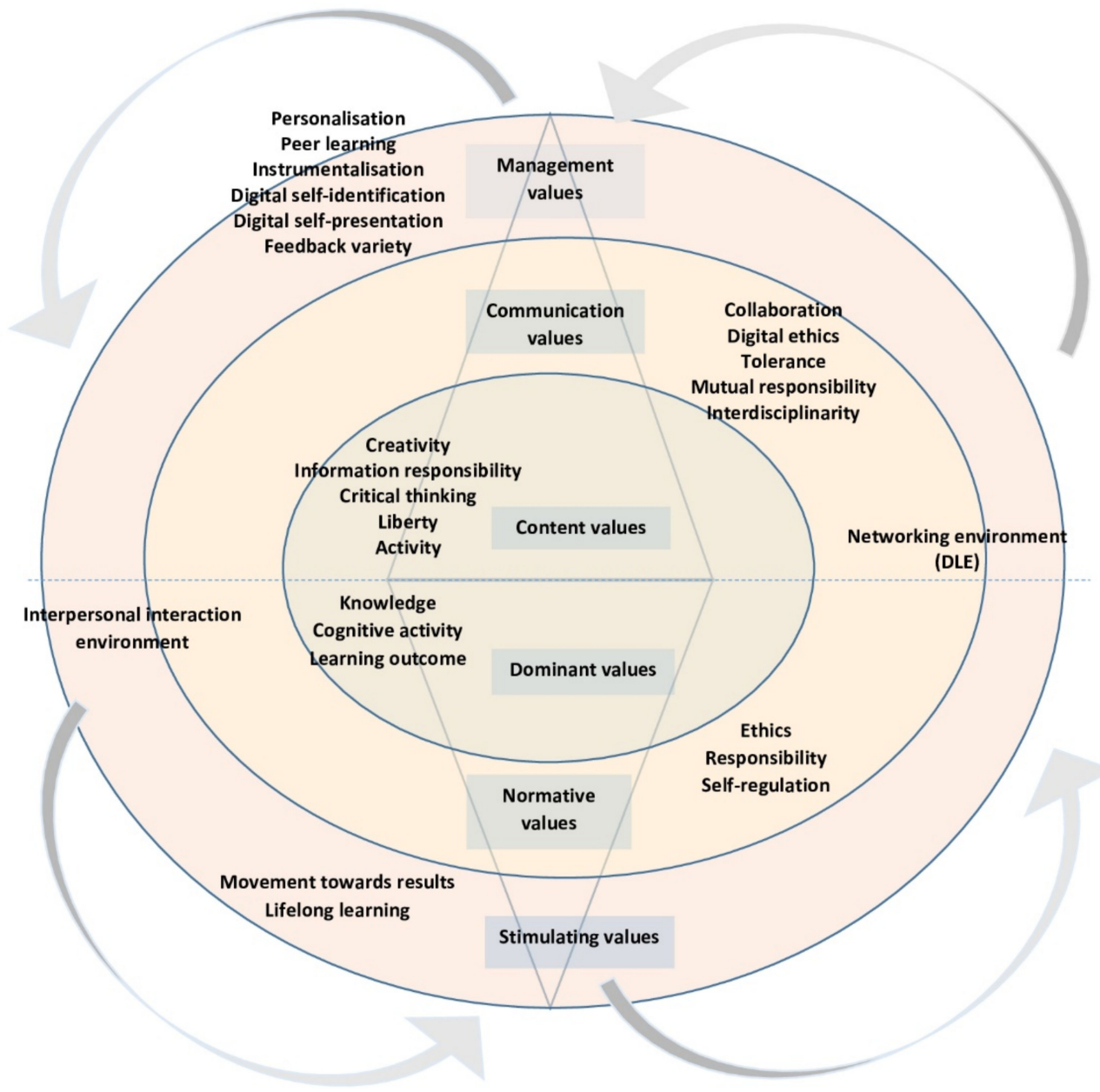

Figure 1. Visualised model of DLE values.

The model shows how the values of the interpersonal interaction environment are reflected and expanded in DLE. The concentric circles of the model combine three groups of values, namely dominant and resource values; regulatory and communication values; and stimulating and managerial values. Thus, it is possible to trace the transformation, development, and enrichment of values when a student is in a blended learning situation that can combine interpersonal and mediated interaction, therefore enhancing the development of specific "digital" values and supporting the development of more traditional professional values for future teachers.

The research started with the following hypothesis: pre-service teachers perceive DLE from the position of the digital content consumer, which is reflected in the awareness of the relevant values. The vector of professional self-realisation, therefore, will be associated with the transition to understanding the environment from the position of an actor and with the perception of the values corresponding to such a position.

\subsection{Sample and Instruments}

The research of DLE values of pre-service teachers took place in 2020-2021 at Herzen University. To identify the DLE values, a survey of 200 respondents (pre-service teachers, i.e., students of the "Pedagogical education" programme, who are supposed to get a job at school after graduation) was conducted. The sample included equal proportions of students 
from all four years of bachelor study (50 people from each course). The questionnaire was created with Google Forms. When the number of respondents of each year of the study reached 50, the data collection function was closed. All respondents had an idea of the concept of "digital learning environment" by the time of participation in the survey, as these issues are included in the content of their basic academic disciplines and they experienced both blended and full-fledged e-learning due to the pandemic. The survey included a list of the DLE opportunities and values (presented in Table 1; the questionnaire template is available in Appendix A). The respondents were asked to evaluate a subjective significance (value) of each category on a 5-point scale (1 point-absolutely irrelevant, 2 points-irrelevant, 3-sometimes relevant, 4-relevant, 5-very relevant). Methods of descriptive statistics and correlation analysis were used to analyse the data, and a cluster analysis was applied to visually represent the relationships between the studied variables, as well as their grouping.

\section{Results}

\subsection{Descriptive Analysis}

Table 2 shows basic statistics for the 27 variables studied.

Table 2. Basic statistics.

\begin{tabular}{|c|c|c|c|c|}
\hline & Variables & Mean & Median & Std. Dev. \\
\hline 1. & Content creation & 4.2 & 4 & 0.91 \\
\hline 2. & Content curation & 4.2 & 4 & 0.96 \\
\hline 3. & Content openness & 4.5 & 5 & 0.79 \\
\hline 4. & Interactivity & 4.4 & 5 & 0.85 \\
\hline 5. & Gamification & 4.5 & 5 & 0.90 \\
\hline 6. & Content multimodality & 4.5 & 5 & 0.86 \\
\hline 7. & Content variety & 4.3 & 5 & 0.93 \\
\hline 8. & Customisation & 3.8 & 4 & 1.17 \\
\hline 9. & Information responsibility & 3.9 & 4 & 1.03 \\
\hline 10. & Digital empathy & 3.8 & 4 & 1.16 \\
\hline 11. & Collaboration & 4.1 & 4 & 1.14 \\
\hline 12. & Netiquette & 4.3 & 5 & 0.99 \\
\hline 13. & Interdisciplinary communication & 4.0 & 4 & 1.05 \\
\hline 14. & Intercultural communication & 4.2 & 5 & 1.06 \\
\hline
\end{tabular}


Table 2. Cont.

\begin{tabular}{|c|c|c|c|c|}
\hline & Variables & Mean & Median & Std. Dev. \\
\hline 15. & Digital tolerance & 4.4 & 5 & 0.92 \\
\hline 16. & Intellectualisation of communication & 4.2 & 5 & 0.97 \\
\hline 17. & Visualisation of communication & 4.0 & 4 & 1.24 \\
\hline 18. & Expansion of communication & 4.2 & 5 & 1.06 \\
\hline 19. & Digital self-management & 4.4 & 5 & 0.82 \\
\hline 20. & Digital self-presentation & 3.9 & 4 & 1.18 \\
\hline 21. & Digital self-identification & 3.9 & 4 & 1.10 \\
\hline 22. & Range of feedback strategies & 3.9 & 4 & 0.94 \\
\hline 23. & Peer learning & 4.1 & 4 & 1.10 \\
\hline 24. & Intellectualisation & 4.0 & 4 & 1.08 \\
\hline 25. & Personalisation & 4.4 & 5 & 0.88 \\
\hline 26. & Instrumentalisation & 4.1 & 4 & 1.03 \\
\hline 27. & Feedback variety & 4.3 & 5 & 1.08 \\
\hline
\end{tabular}

The results obtained show that, in general, the possibilities of the digital educational environment are perceived by future teachers as significant and valuable (Mean $\geq 3.9$ ). The group of variables 1-9 (digital content values) has both the highest and the lowest values. The greatest value is presented by opportunities such as openness and multimodality of content and gamification. This is followed by the interactivity and variability of content and the ability to create and curate it. The variables "information responsibility" and "customisation" have the smallest values.

The group of variables 10-18 (communication values) has less balanced values. The variable "digital empathy" has the least value, and the highest value is "digital tolerance". In general, at this stage, the communication capabilities of DLE are significant for future teachers, but they are inferior in value to resource capabilities.

The group of variables 19-27 (management values) has the lowest values on average. The least valuable were digital self-presentation, digital self-identification, and a range of management strategies, while the most significant were digital self-management, personalisation, and a variety of feedback.

\subsection{Correlations and Cluster Analysis}

In the "resource values" group of variables, the most significant correlations were found between variables 1 and 2 (content creation and curation), $r=0.63$. They form a cluster that characterises the activity of an individual as an author of digital content. Variables 4 and 5 (interactivity and gamification), $r=0.63$, merging with variable 6 (content multimodality), form a cluster associated with content interactivity and attractiveness. 
Variables 7 (content variety), 9 (information responsibility), and 8 (customisation) form a cluster that is more related to personalisation. This agglomeration also includes information responsibility.

The combination of variables in the "communication values" group is also interesting. The first cluster is formed by variables associated with the implementation of joint activities in the digital environment including digital empathy, collaboration and interdisciplinary and intercultural communication. The most significant correlations were found between variables 13 and 14 (interdisciplinary, intercultural communication), $\mathrm{r}=0.68$. The second cluster is formed by variables characterizing new digital communication toolsintellectualisation, visualisation of communication, expansion of communication links. The third cluster is the variables of the ethical side of interaction-netiquette and digital tolerance.

Variables of the "management values" group also form three clusters. The first cluster is formed by variables associated with digital management tools-24, 25, 26 (intellectualisation, personalisation, and instrumentalisation). The second cluster is formed by variables from the interaction area-22, 23, 27 (a range of feedback, peer learning, and variety of feedbacks). Moreover, significant correlations were found between variables 22 and 23 . The third cluster can be called "self-knowledge in the DLE" and it combines variables 19, 20, 21 (digital self-management, self-presentation, self-identification).

Thus, the analysis made it possible to identify pre-service teachers' value mindsets in terms of DLE.

Firstly, pre-service teachers perceive digital content values as active, involved users, who are willing to satisfy their cognitive interests but not as content authors and creators. They are willing to consume ready-made multi-format content, but not to create it. The digital responsibility score is comparatively lower than the pursuit of interactivity and gamification.

Secondly, among the values of communication, tolerance comes to the fore, and that can be interpreted both as a desire to have an opinion and as a need to accept the behavior of others. However, the value of empathy is comparatively lower, and that may indicate an unwillingness to perceive and understand other stakeholders (an egocentric orientation).

Thirdly, in the aspect of management values, the ability to independently manage DLE resources and communications (feedback and comfortable customisation) comes to the fore, and not the willingness to understand oneself and present a personal digital image to others while solving personal, educational, and professional tasks.

\section{Discussion}

Quite a lot of research has been carried out on various aspects related to the professional values of teachers and DLE issues. Reinhold et al. [40] studied the relationship between the use of digital tools, teacher self-efficacy, and perception of digital tools value. They distinguished three teacher orientations for teaching mathematics with digital tools- "nervous experts, confident advocates, and skeptical novices". Therefore, teachers' motivational and emotional orientations (value, self-efficacy, and anxiety) are important for successful professional self-realisation. Higueras-Rodríguez et al. [41] paid attention to the educational value of social networks, specifically for Twitter, and found that the main values include gamification and interactivity. Kucirkova et al. [42] reached values through the study of personalisation of the educational environment in a broad sense. However, in this research, the authors study values that are also appropriate for DLE content—customisation, individualisation, and adaptation. FitzGerald et al. [43] also name personalisation among the main dimensions of technology-enhanced learning.

We can say that awareness of the DLE opportunities and values takes place in the process of teacher practical activity and this awareness has a significant impact on the style of work, its effectiveness, and, consequently, professional self-realisation. For example, Hadad et al. [44] showed that the experience of teaching in a Small Private Online Course contributed to the switch from low-productivity and labor-intensive teaching strategies of 
"tinkering, debugging" to experiential learning and collaborative learning. A study of the practicing teachers' activities in DLE and its specific characteristics in a pandemic showed that the main difficulties were recorded with the design of educational programs and curricula, application of modern educational facilities, organisation of students' autonomous work, and productive communication with students [45]. Therefore, practicing teachers are not fully aware of DLE possibilities and values, and they cannot create conditions for future teachers' full-fledged training for professional activities in such an environment.

Sakalli et al. [46] concluded that such values as tolerance exist not only in the physical environment but also in the virtual environment. Rezer researched students' social values in the situation of digital learning during the pandemic and found that "the global digitalisation of education in conditions of the COVID-19 pandemic can influence the formation of instrumental values of higher school students while the virtual transfer of knowledge and experience by teachers" [47] p. 229. For example, values such as a sense of duty, self-control, and responsibility decreased in the situation of online learning. However, values such as good manners, cheerfulness, and independence did not decrease. Therefore, the results correlate with the findings of this study on the need for increased attention to issues of digital responsibility and understanding of the positions of other DLE stakeholders in the broad sense.

The limitations of this particular study are related to the national and socio-cultural conditions of higher education in Russia, together with the particular case of Herzen University. The experience of using digital technologies in teacher training may differ regionally, for example, in large cities such as Saint-Petersburg, this experience is more intense. In addition, pedagogical universities in Russia have different practices in implementing projects related to the use of digital technologies, and the technical base and equipment may differ. For example, Herzen University has a Technopark of universal pedagogical competencies equipped with robotics and augmented reality that implements a programme "Modern Practices of IT Education". Nevertheless, the findings can be beneficial for other universities in terms of e-learning practices, DLE design, and the facilitation of internships. The listed limitations can help to figure out the prospects for further research-a comparative intercultural study of pre-service teachers' DLE values. It would be also interesting to compare the characteristics of the pre-service teachers and practicing teachers (with different work experience) values.

\section{Conclusions}

The research hypothesis was proved in our study. Pre-service teachers perceive DLE from the position of the digital content consumer, which is reflected in the awareness of the relevant values-values of various, interactive gamified digital content, together with the tolerance to other environmental stakeholders as content consumers. The vector of professional self-realisation, therefore, is associated with the transition to understanding the environment from the position of an actor and with the perception of the values corresponding to such a position-values of a content creator and curator, ready to collaborate and show empathy to other stakeholders, to understand oneself through self-analysis of digital footprints and digital self-presentation.

In conclusion, let us formulate the answers to the proposed research questions.

What is the value structure of the DLE and how it can be modeled? The value structure of the DLE comprises three groups of values that evolve from its digital content opportunities, interaction features, and management peculiarities. Based on the main feature of the DLE-its mobility, instrumentality, and the network principle of constructionit is possible to model its value structure. Thus, in various situations of pre-service teacher education, depending on the courses and content studied, it is possible to focus on the appropriate professional values.

How do students (particularly, pre-service teachers) perceive the DLE values from the professional standpoint? What aspects and opportunities of the environment are students aware of in a sufficient and insufficient measure? Firstly, from a professional 
perspective, pre-service teachers lack awareness of digital content creation. Therefore, during the internship, they might not pay enough attention to this issue when working with children. Secondly, pre-service teachers need extra practical experience associated with digital empathy. In particular, it is necessary to offer them tasks related to the perception of a learner through digital footprints (e.g., students' works, social media content) and moderation of virtual discourses. Thus, a future teachers will be ready to effectively interact not only face to face, but also in DLE. Thirdly, a special group of skills for a modern teacher is associated with digital self-presentation. This new area of professional tasks includes not only ethical issues but also issues of finding a common language with the modern generation, broadcasting human and professional values with digital language and tools.

Which areas of professional training toned to be strengthened and adjusted? In addition, how can the conditions for the effective development of pre-service teachers' professional competencies that will provide successful professional self-realisation be created? Professional training for pre-service teachers should include modern educational practices focused both on traditional face-to-face and mediated, virtual interaction. In such a situation, a teacher will be able to master an expanded set of competencies that will lead to successful professional self-realisation in new areas of education-as a designer of consciousness training tools, educational online platform coordinator, moderator, mind fitness coach, etc. [48]. Thus, the teacher will become competitive in the labor market for the digital economy.

Funding: This research was funded by the Ministry of Science and Higher Education of the Russian Federation, project No. FSZN-2020-0027.

Institutional Review Board Statement: Not applicable.

Informed Consent Statement: Not applicable.

Data Availability Statement: The data presented in this study are available on request from the author.

Conflicts of Interest: The author declares no conflict of interest.

\section{Appendix A}

The questionnaire template

Dear students!

You are invited to take part in a survey aimed at exploring the values of the digital learning environment.

You will be offered several opportunities for the digital learning environment.

Please, evaluate how each of these opportunities is valuable for you like the digital learning environment stakeholder.

Rate a subjective significance (value) of each category on a 5-point scale (1 point-absolutely irrelevant, 2 points-irrelevant, 3-sometimes relevant, 4-relevant, 5-very relevant)

The survey is anonymous.

Thank you for participating!

1. Content creation (the opportunity to create digital content and post it in the environment, independently change and update the content of the environment)

2. Content curation (the opportunity to collect and select meaningful content, describe and organise it for re-publication, for example, collecting and publishing useful web links on a selected topic)

3. Content openness (the opportunity to work with open Internet resources)

4. Interactivity (the opportunity to interact with objects and content of the environment)

5. Gamification (the opportunity to participate in games, apply game elements, interact with virtual assistants)

6. Content multimodality (the opportunity to choose the form of obtaining and presenting information—audio, video, text, etc.) 
7. Content variety (the opportunity to choose different sources of information-text documents, electronic textbooks, references, methodological literature, etc.)

8. Customisation (the opportunity to customise the interface, a personal profile, etc.)

9. Information responsibility (the opportunity to show responsibility for information and educational materials published in the environment)

10. Digital empathy (the opportunity to "see", understand other participants in the digital environment through their actions, traces of activity, activity)

11. Collaboration (the opportunity to work in a team, help each other, be responsible for achieving a common result)

12. Netiquette (compliance with the rules of network behaviour and interaction)

13. Interdisciplinary communication (the opportunity to interact with representatives of other areas of study or other types of professional activity)

14. Intercultural communication (the opportunity to interact with representatives of other peoples, cultures)

15. Digital tolerance (the opportunity to show tolerance for different opinions, views, worldviews, lifestyles, etc. of other stakeholders in the environment)

16. Intellectualisation of communication (the opportunity to use the collective intelligence of the participants in the environment to achieve the goal, participation in the network community)

17. Visualisation of communication (the opportunity to quickly interact with participants in the environment using emoticons, signs, symbols, memes, videos, etc.)

18. Expansion of communication (the opportunity to interact $24 / 7$, through synchronous and asynchronous forms of communication)

19. Digital self-management (the opportunity to manage one's educational activities, independently organise, plan and control the learning process)

20. Digital self-presentation (the opportunity to create your image in the environment, to present your educational achievements in the environment)

21. Digital self-identification (the opportunity to know and better understand yourself through your actions in the environment)

22. Range of feedback strategies (the opportunity to get feedback, on the actions performed in the environment-from colleagues, teachers, third-party users of the environment, from the information system)

23. Peer learning (the opportunity to work in a team, teach others and learn from others yourself, evaluate the process and results of the activities of others)

24. Intellectualisation (the opportunity to work with intelligent technologies-intelligent search engines, intelligent translators, machine learning, etc.)

25. Personalisation (the opportunity to build your personal, individual educational route of study following your needs and interests)

26. Instrumentalisation (the opportunity to use ICT tools to solve a variety of educational tasks, for example, mastering the content of the environment, organizing network communication, planning and monitoring educational activities, etc.)

27. Feedback variety (the ability to choose different types of the learning process management in the environment-external, mutual, self-management)

\section{References}

1. VUCA World. Available online: https:// www.vuca-world.org/ (accessed on 18 December 2021).

2. Núñez-Canal, M.; de Obesso, M.D.L.M.; Pérez-Rivero, C.A. New challenges in higher education: A study of the digital competence of educators in COVID times. Technol. Forecast. Soc. Chang. 2022, 174, 121270. [CrossRef]

3. Mehla, L.; Sheorey, P.A.; Tiwari, A.K.; Behl, A. Paradigm shift in the education sector amidst COVID-19 to improve online engagement: Opportunities and challenges. J. Global Inf. Manag. 2021, 30, 1-21. [CrossRef]

4. Withers, J.D.A.; Sik-Lanyi, C. Sustaining inclusive, quality education during COVID-19 lockdowns. Sustainability 2021, 13, 13481. [CrossRef]

5. Weidlich, J.; Kalz, M. Exploring predictors of instructional resilience during emergency remote teaching in higher education. Int. J. Educ. Technol. High. Educ. 2021, 18, 43. [CrossRef] [PubMed] 
6. $\mathrm{Wu}, \mathrm{B} . ;$ Peng, X.; Hu, Y. How to foster pre-service teachers' STEM learning design expertise through virtual internship: A design-based research. Educ. Technol. Res. Dev. 2021, 69, 3307-3329. [CrossRef]

7. Theelen, H.; Willems, M.C.; van den Beemt, A.; Conijn, R.; den Brok, P. Virtual internships in blended environments to prepare preservice teachers for the professional teaching context. Br. J. Educ. Technol. 2020, 51, 194-210. [CrossRef]

8. Tudini, D.V.; Dooly, D.M. Complaining for rapport building: Troubles talk in a preservice language teacher online video exchange. Linguist. Educ. 2021, 64, 100941. [CrossRef]

9. Luís, A.R. The development of pre-service Teacher's reflection skills through video-based classroom observation. Adv. Intell. Sys. Comput. 2020, 1161, 263-270. [CrossRef]

10. Akimova, O.; Dorozhkin, E.; Chapaev, N.; Kiseleva, A.; Stroganova, A. Determination of the elements of architecture students' readiness to conduct professional activities. Int. J. Engi. Pedagog. 2021, 11, 102-117. [CrossRef]

11. Samoderzhenkov, A.N.; Kardanova, E.; Satova, A.K.; Orel, E.A.; Kulikova, A.A.; Mombiyeva, G.A.; Kazakhbaeva, G.I.; Duisenbayeva, A.O. Measuring Teacher Students' Psychological Readiness for Professional Life. Vopr. Obraz. 2021, 3, 114-137. [CrossRef]

12. Chao, T.; Sung, Y.; Hsu, M. Construction of the work values scale for teachers. J. Res. Educ. Sci. 2018, 63, 163-196. [CrossRef]

13. Zabolotska, O.; Zhyliak, N.; Hevchuk, N.; Petrenko, N.; Alieko, O. Digital competencies of teachers in the transformation of the educational environment. J. Optim. Ind. Eng. 2021, 14, 43-50. [CrossRef]

14. Rokeach, M. The Nature of Human Values; The Free Press: New York, NY, USA, 1973.

15. Schwartz, S.H. Universals in the Content and Structure of Values: Theoretical Advances and Empirical Tests in 20 Countries. Adv. Exp. Soc. Psychol. 1992, 25, 1-65.

16. Szydło, J.; Grześ-Bukłaho, J. Relations between national and organisational culture—Case study. Sustainability 2020, 12, 1522 [CrossRef]

17. Farcane, N.; Deliu, D.; Bureană, E. A Corporate Case Study: The application of Rokeach's value system to corporate social responsibility (CSR). Sustainability 2019, 11, 6612. [CrossRef]

18. Hanel, P.H.P.; Litzellachner, L.F.; Maio, G.R. An empirical comparison of human value models. Front. Psychol. 2018, 9, 1643 [CrossRef]

19. Baeva, I.A.; Gayazova, L.A.; Kondakova, I.V. Personality resources of adolescents in the educational environment. Integr. Educ. 2021, 25, 482-497. [CrossRef]

20. Wetzelhütter, D.; Nnebedum, C.; De Wet, J.; Bacher, J. Testing a modified version of Schwartz's portrait values questionnaire to measure organisational values in a university context. J. Hum. Values 2020, 26, 209-227. [CrossRef]

21. Pishchik, V.I. Value-semantic bases of ideas about the profession and satisfaction with the profession of higher school teachers. Int. J. Cogn. Res. Sci. Eng. Educ. 2020, 8, 69-81. [CrossRef]

22. Tuulik, K.; Õunapuu, T.; Kuimet, K.; Titov, E. Rokeach's instrumental and terminal values as descriptors of modern organisation values. Int. J. Org. Lead. 2016, 5, 151-161. [CrossRef]

23. Lubsky, A.V.; Zaytseva, A.A. Social behavior of students in higher education (based on the results of a sociological study in the Rostov region, Russia). Univers. J. Edu. Res. 2020, 8, 4529-4535. [CrossRef]

24. Litvinova, T.; Vershinina, O.; Moskvitin, G. Social and political attitudes of Moscow students on the background of the all-Russia and regional youth studies. Soc. Sci. 2020, 9, 153. [CrossRef]

25. Ledovskaya, T.V.; Solynin, N.E.; Khodyrev, A.M. Development of initial teacher education students' sets of values during pursuing undergraduate degrees. Sci. Edu. Today 2019, 9, 7-23. [CrossRef]

26. Mcgill, M.M.; Zarch, R.; Sexton, S.; Smith, J.M.; Ong, C.; Rasberry, M.; Hollis, S. Evaluating Computer Science Professional Development for Teachers in the United States; ACM International Conference Proceeding Series; Association for Computing Machinery: New York, NY, USA, 2021; pp. 966-974, Article 11. [CrossRef]

27. Shevtsiv, Z.; Yevtuch, M.; Filonenko, M.; Pelekh, Y.; Muszkieta, R.; Zukow, W. Identification of positive individual qualities of an inclusive education future specialist during professional training. J. Phys. Educ. Sport 2020, 20, 966-974. [CrossRef]

28. Wu, S.M. Development and application of the measures of school value, teacher autonomy, and teacher motivation. New Educ. Rev. 2015, 39, 240-250. [CrossRef]

29. Li, Y.; Gu, J.; Wang, L. Research on artificial intelligence ethics in the field of art design. J. Phys. Conf. Ser. 2020, $1673,012052$. [CrossRef]

30. Odinokaya, M.; Krepkaia, T.; Sheredekina, O.; Bernavskaya, M. The Culture of Professional Self-Realisation as a Fundamental Factor of Students' Internet Communication in the Modern Educational Environment of Higher Education. Edu Sci. 2019, 9, 187. [CrossRef]

31. Digital Competence Framework for Educators. Available online: https://ec.europa.eu/jrc/en/digcompedu (accessed on 18 December 2021).

32. European Commission. Science Hub-The Digital Competence Framework 2.0. Available online: https://ec.europa.eu/jrc/en/ digcomp/digital-competence-framework (accessed on 16 December 2021).

33. The Order on the Approval of the Federal State Educational Standard of Higher Education in a Bachelor's Degree in the Direction 44.03.01 Pedagogical Education. Available online: http://fgosvo.ru/uploadfiles/FGOS\%20VO\%203++/Bak/440301_B_3_160320 18.pdf (accessed on 18 December 2021).

34. Gil-Quintana, J.; Vida de León, E. Educational influencers on Instagram: Analysis of educational channels, audiences, and economic performance. Publications 2021, 9, 43. [CrossRef] 
35. Vasodavan, V.; DeWitt, D.; Alias, N.; Noh, M.M. E-moderation skills in discussion forums: Patterns of online interactions for knowledge construction. Pertanika J. Soc. Sci. Humanit. 2021, 28, 3025-3045. [CrossRef]

36. Martin, B.A. Teachers perceptions of google classroom: Revealing urgency for teacher professional learning. Can. J. Learn. Technol. 2021, 47, 1-16. [CrossRef]

37. Jitpaisarnwattana, N.; Reinders, H.; Darasawang, P. Understanding the roles of personalisation and social learning in a language mooc through learning analytics. Online Learn J. 2021, 25, 244-263. [CrossRef]

38. Yates, A.; Starkey, L.; Egerton, B.; Flueggen, F. High school students' experience of online learning during COVID-19: The influence of technology and pedagogy. Technol. Pedagog. Educ. 2021, 30, 59-73. [CrossRef]

39. Noskova, T. Didactics of the Digital Environment; The Herzen University Publishing House: St. Petersburg, Russia, 2020; 383p, ISBN 978-5-8064-2981-1.

40. Reinhold, F.; Strohmaier, A.; Finger-Collazos, Z.; Reiss, K. Considering teachers' beliefs, motivation, and emotions regarding teaching mathematics with digital tools: The effect of an in-service teacher training. Front. Educ. 2021, 6. [CrossRef]

41. Higueras-Rodríguez, L.; Medina-García, M.; Martínez-Valdivia, E. Treatment and evaluation of game as a didactic resource in the communication of teachers through social networks. Eur. J. Educ. Res. 2021, 10, 2105-2119. [CrossRef]

42. Kucirkova, N.; Gerard, L.; Linn, M.C. Designing personalised instruction: A research and design framework. Br. J. Educ. Technol. 2021, 52, 1839-1861. [CrossRef]

43. FitzGerald, E.; Kucirkova, N.; Jones, A.; Cross, S.; Ferguson, R.; Herodotou, C.; Hillaire, G.; Scanlon, E. Dimensions of personalisation in technology-enhanced learning: A framework and implications for design. Br. J. Educ. Technol. 2018, 49, 165-181. [CrossRef]

44. Hadad, S.; Shamir-Inbal, T.; Blau, I.; Leykin, E. Professional development of code and robotics teachers through small private online course (SPOC): Teacher centrality and pedagogical strategies for developing computational thinking of students. J. Educ. Comput. Res. 2021, 59, 763-791. [CrossRef]

45. Batrakova, I.S.; Glubokova, E.N.; Pisareva, S.A.; Tryapitsyna, A.P. Changes in university teacher's pedagogical activity in the context of digitalisation of education. Vyss. Obraz. V Ross. 2021, 30, 9-19. [CrossRef]

46. Sakalli, Ö.; Tlili, A.; Altınay, F.; Karaatmaca, C.; Altınay, Z.; Dağlı, G. The role of tolerance education in diversity management: A cultural historical activity theory perspective. SAGE Open 2021, 11, 21582440211060831. [CrossRef]

47. Rezer, T.M. Social Values of Students in Conditions of Digitalisation of Education and COVID-19. Integr. Obr. 2021, 25, 226-243. [CrossRef]

48. Atlas of Emerging Jobs. Available online: https://atlas100.ru/en/ (accessed on 17 December 2021). 